\title{
Resenha: análise da perspectiva comportamental e de 'ethos profissional' no estudo das políticas públicas de humanização do parto.
}

\author{
Wanessa Oliveira Silva ${ }^{1}$
}

MAIA, Mônica Bara. Humanização do parto: política pública, comportamento organizacional e ethos profissional. Rio de Janeiro: Fiocruz, 2010.

Resenha:

Os estudos de Mônica Bara Maia a respeito dos enfrentamentos ocorridos para a implantação das políticas públicas de humanização do parto, que culminaram com sua dissertação de mestrado em Ciências Sociais pela Pontifícia Universidade Católica (PUC- Minas) e, posteriormente, com a obra "Humanização do Parto: Política Pública, Comportamento Organizacional e Ethos Profissional", são destrinchados a partir da compreensão de três fatores interligados: as políticas públicas que normatizam uma assistência humanizada, organizações hospitalares envolvidas num modelo tecnocrático a serem atingidas por essas políticas e, por fim, os profissionais da saúde e suas práticas. Com o intuito de analisar os constrangimentos e facilitações na aplicação das normativas, a autora opta por situar as políticas públicas dentro da categoria sociológica do novo institucionalismo; já as práticas dos médicos e a relação com enfermeiras é analisada nos parâmetros do ethos profissional. A organização hospitalar, por fim, é situada como um local intermediário entre as normativas e o trabalho dos profissionais da assistência. Em uma perspectiva eminentemente empírica e, por certo, também de saber militante, os elementos de reflexão apresentados pela autora se estendem para além do muro acadêmico e seus vícios de autocentralidade, ao tempo em que não se pode acusá-la de um panfletarismo verborrágico, conforme nos garantiu o cientista político Carlos Aurélio Pimenta de Faria, ao

1 Mestranda do Programa de Pós-Graduação em Sociologia da Universidade Federal de Alagoas (PPGS-UFAL). E-mail: nessa_rr@hotmail.com

Latitude, Vol. 8, no 1, pp. 211-227, 2014

DOI: https://doi.org/10.28998/2179-5428.20140108 
Resenha: análise da perspectiva comportamental e de 'ethos profissional' no estudo das políticas públicas de humanização do parto.

apresentar a obra.

Com pesquisas teóricas em que predomina o institucionalismo neoweberiano, a autora compreende o problema a partir de uma diversidade de influências comportamentais, em um movimento cuidadoso de abrangência e profundidade com as especificidades das áreas hospitalares analisadas. Trataremos com mais detalhes cada ponto elencado pela autora e, por fim, traremos nossas conclusões no que diz respeito ao modelo de análise escolhido, seus avanços e limitações.

A elaboração do problema requer a explicação inicial de que o parto, tido como um evento social e cultural, deixou de ser uma experiência íntima, para se tornar uma prática dominada pela medicina, institucionalizada nos hospitais e regulada por políticas públicas. Nada disso, entretanto, garantiu uma melhoria na saúde materna. No primeiro capítulo, a autora se dedica a elaborar um diagnóstico a respeito da Assistência à Saúde e ao Parto no Brasil. Especifica que o modelo de serviço à gestante atual é fragmentado, curativo e hospitalar, o que impacta na elaboração de políticas de atenção ao parto. Esse paradigma tem relação de interdependência e legitimação com o modelo geral de assistência à saúde, cujo caráter excludente e desigual é fornecido em um mix de serviços públicos e privados. Essa situação é explicada historicamente pelo privilégio às práticas médico-hospitalares financiadas pelo sistema previdenciário, em detrimento das ações coletivas de prevenção e promoção à saúde. Os estudos expunham como a medicina suplementar se expandiu com a intervenção estatal na Saúde, já que essa 'universalização' proposta pela Constituição de 1988 se dava, na prática, pela compra de serviços privados por parte do Estado. Atualmente, segundo Maia, um quarto da população é coberta por plano suplementar, estando o Brasil situado como o segundo maior mercado privado de saúde, perdendo apenas para o norte-americano. No que diz respeito à população, prossegue a autora, a cobertura possui uma dicotomia clara, onde, os indivíduos socialmente mais vulneráveis gastam mais com plano de saúde (proporcionalmente à sua renda), embora tenham direito a menor cobertura do seguro e menos acesso à prevenção e promoção da saúde (Maia, 2010, p.27).

Esse hibridismo do sistema brasileiro baseado no complexo médicoindustrial, além de gerar diferentes formas de acesso e estabelecer fortemente a divisão de classes, estimula, ainda, a cultura de valorização da doença e, por conseguinte, a especialização médica, e as intervenções de alta 
tecnologia. O duplo formato de assistência também ocorre na assistência ao parto, onde o modelo tecnocrático se legitima de dois modos diferentes: na assistência privada, através de cirurgias cesarianas; e na assistência pública, através de intervenções desnecessárias e danosas.

A institucionalização do parto e sua formatação ao modelo tecnocrático do hospital, por sua vez, são explicadas a partir do contexto europeu do século XVIII. O parto, em si, não era um evento médico, mas ficava a cargo de parteiras. Apenas em casos de complicação, os cirurgiões - ou cirurgiões barbeiros- eram chamados. Suas técnicas eram ineficazes e quase sempre se limitavam a retirar um feto vivo de uma mãe morta ou vice-versa. Segundo a autora, a obstetrícia só passou a ser praticada quando a primeira faculdade europeia de medicina foi fundada no século XIX, o que fez com que a mulher passasse a ser alvo de interesse médico. O discurso científico se afina em torno de uma definição iluminista da mulher, baseada no determinismo biológico, e sob cuja descrição de sua vida é vista como uma sucessão de fenômenos fisiopatológicos. No fim do século XIX, os médicos já reivindicavam o controle dos partos e sua realização nas recémcriadas maternidades, anexas aos hospitais. Se antes a divisão do trabalho era moldada pela saúde ou não da mulher que paria, agora eles criavam escolas onde as mulheres, que não poderiam exercer a medicina, precisavam frequentar para, então, se tornarem assistentes dos médicos.

Por fim, Estado, Igreja e elite médica reforçavam ainda mais a expulsão através do discurso de que as parteiras eram sujas. Ironicamente, o que se verificou foi um crescimento na morte de mulheres e bebês dentro dos hospitais, em geral por infecções puerperais desenvolvidas através das péssimas condições de higiene das maternidades. Desse modo, até 1870, apenas mulheres pobres buscavam os espaços hospitalares, a fim de também encontrarem assistência e caridade. Segundo a autora, a relutância média em reconhecer a iatrogenia ${ }^{2}$ das suas práticas atrasou em mais de 100 anos o combate às infecções, que só começou a ser minimizado após o simples ato dos médicos de assepsiar o local.

2 Iatrogenias são definidas e repetidas diversas vezes durante toda a obra como complicações de saúde provenientes da própria prática ou procedimento médico, demandando mais tratamentos. Grande parte das complicações do parto são causadas, atualmente, por intervenções médicas sem qualquer evidência científica, que culminam em iatrogenias como parada de progressão, aumento de pressão, infecções por cortes desnecessários, etc. 
Resenha: análise da perspectiva comportamental e de 'ethos profissional' no estudo das políticas públicas de humanização do parto.

O parto hospitalar serviu, por fim, ao que se buscou: restringiu a competição com parteiras, fez crescer o controle médico sobre pacientes, estabeleceu o treinamento para novos médicos e, por fim, gerou a especialização. No Brasil, o ensino à prática da Obstetrícia era precário até o fim do século XIX, onde ainda predominavam os partos domiciliares. Mulheres brancas e ricas buscavam médicos para atender em domicílio; mulheres pobres com algum recurso buscavam as parteiras; já mulheres inseridas em condição de miséria e abandono procuravam os hospitais e maternidade. Entre as práticas, desenvolvidas até hoje, estão o deslocamento da mulher em espaços distintos da maternidade, segundo as fases do processo de parturição; o intenso aparato tecnológico e fármacoquímico. A cesárea passou a ser vendida como desejo de consumo, fazendo com que médicos atribuissem o número alto a uma escolha por parte das mulheres, criando a chamada 'cultura da cesárea'. Entretanto, esse argumento foi considerado infundado. Várias pesquisas de abrangência nacional comprovaram que a escolha das mulheres tendia, contraditoriamente ao discurso médico, à escolha pelo parto normal. Em 2000, o Plano de Humanização do Parto Normal (PHPN) ampliou as normativas, entretanto, a dualidade da tecnocracia se sobrepôs às boas intenções. O entendimento que a autora chegou foi o de que não é possível questionar o modelo de atenção que, por sua vez, não pode ser desvinculada da lógica do processo de trabalho na organização hospitalar e seu modo de inserção no sistema.

No segundo capítulo, a autora se debruça sobre o entendimento da instituição da organização hospitalar e das relações das profissões na análise dos enfrentamentos para a implementação da política pública de humanização do parto. Maia desenvolve seu argumento a partir de estudos sobre como se dá a execução de políticas públicas e a perturbação burocrática e societária que se segue às novas regulamentações. Para tanto, parte para explicar a execução de política pública como uma mudança de conduta com base nas prescrições de autoridades competentes, cujas faces podem se definir pela orientação normativa para mudanças de ações e dos atores. No que diz respeito às políticas de humanização, segundo a autora, as perturbações ocorrem tanto para os agentes, como médicos e instituições, como para os pacientes, que são as gestantes e familiares.

Mudar o modelo do parto médico-hospitalar tecnocrático requer, para além de efeitos éticos, uma mudança no processo de trabalho dos 
profissionais, o que, segundo a autora, acontece fazendo com que os profissionais deixem suas 'crenças e valores' atuais, para dar lugar a um novo sistema de crenças e valores. Segundo a autora, nas maternidades públicas ainda há mecanismos de controle para verificar a implementação da política pública, como os conselhos e ouvidorias, de modo que cada hospital responderia 'à sua maneira' às normativas. Já as mulheres que buscam o setor privado, cuja obediência serve apenas ao mercado, são submetidas a mais riscos. A autora segue, então, à observância de um dos fatores da execução das políticas: o comportamento dos executores, os profissionais, e a organização hospitalar, extremamente heterogênea em relação ao SUS. Para a autora, esses elementos podem ser condensados na noção de ethos.

Maia começa afirmando que o hospital não é uma categoria passível de generalização por se tratar de uma 'materialização de sentidos, objetivos, valores e procedimentos diversos'. A assistência instrumentalizada e medicalizada, centrada na organização do hospital, é historicizada pela autora após o golpe militar de 1964. Quando o Estado teve as contas saturadas pela compra de serviços de hospitais privados, passou então a construir 'imensos hospitais' e contratar trabalhadores da saúde por salários extremamente baixos para atenderem serviços emergenciais. Os hospitais universitários são caracterizados prioritariamente como prolongamento do estabelecimento de ensino em saúde e como espaços de atendimentos de maior complexidade. Sao tipicamente financiados pelo Ministério da Educação (MEC) e pelo Ministério da Saúde (MS). Atualmente, há 44 deles vinculados às Instituições Federais de Ensino Superior (Ifes). É nos hospitais universitários, segundo a autora, que já se inicia o modelo de valorização da tecnologia, especialização, fragmentação do processo de trabalho, além de formação de médicos incapazes de atuar com clínica integral. Financiado com dinheiro público, há várias queixas no sentido do distanciamento entre academia e prestação de serviços que solucionem a crise na Saúde.

A remuneração mais comum dos serviços hospitalares ao SUS e da saúde complementar brasileira, segundo Maia, é o pós-pagamento, ou seja, o pagamento 'por produção'. O modelo é alvo de críticas porque desconsidera os esforços e resultados obtidos, incentiva as iatrogenias, e estimula o hospital a manter o custo do tratamento abaixo do preço estabelecido em tabela, aumentando a demanda por eficiência e reduzindo 
Resenha: análise da perspectiva comportamental e de 'ethos profissional' no estudo das políticas públicas de humanização do parto.

os recursos que seriam adequados. Quanto mais invasivo, tecnológico, e alto no valor tabela, maior o potencial de lucratividade do procedimento. Estimulam, por fim, o desperdício, o intervencionismo, investimentos acríticos em tecnologia e mais voltados ao aspecto mercadológico do que aos interesses em saúde pública ou às soluções nos problemas hospitalares ${ }^{3}$

A assistência à saúde prestada no hospital é realizada principalmente por profissionais da medicina e da enfermagem. A profissão, enquanto categoria analítica, é mencionada com o auxílio da discussão sobre ethos, para então chegar até a compreensão das desigualdades e hierarquias entre medicina e enfermagem. De um lado, o modelo tecnocrático centra o médico. Do outro, as políticas de humanização trazem à tona as enfermeiras obstétricas para partos sem complicações.

Ao recorrer ao conceito de profissão, enquanto categoria analítica, a autora apresenta os conceitos a partir dos quais profissão é definida como ocupação baseada em um domínio de um corpo de conhecimentos teóricos e práticos complexos transmitidos através de cursos e capacitações, levando a distinção (e a autonomia) entre profissional e leigo. As profissões se organizam em corporações que buscam autorregulação e regulação de mercado, o que inclui a intenção de manter o monopólio sobre determinadas funções. O vocabulário grego ethos, nesse sentido, é trazido enquanto um sistema de aspectos cognitivos, morais, e estéticos de uma cultura, que designam o que conhecemos por 'visão de mundo'. A relação circular e dialética entre ethos e visão de mundo entende que as conclusões normativas dos indivíduos são retiradas a partir de premissas factuais, enquanto que as conclusões factuais são retiradas de premissas normativas.

O ethos, ao tempo em que imporia limitações e constrangimentos, também abre espaços para mudanças, permanências e recorrências. $\mathrm{O}$ conceito de ethos é utilizado, portanto, como resultante da dialética entre estrutura e agência, tradição e mudança. E, portanto, para a autora, pôde ser utilizado para se pensar a prática profissional. Segundo Maia, as

3 A autora expunha um exemplo bem extremo. A apuração de que o SUS paga cerca de R $\$ 52$ mil para um transplante de fígado, quando seu custo é de $R \$ 16$ mil. Na crise hipertensiva, o paradoxo: é pago $\mathrm{R} \$ 120$ no tratamento, quando o custo é de $R \$ 660$. Já quantos aos partos, enquanto o custo do parto normal variava entre $R \$ 486$ e $R \$ 535$, se pagava $R \$ 315$. Já as cesáreas, que custavam de $R \$ 753$ a $R \$ 780$, os pagamentos limitavam-se a $R \$ 689$. 
categorias profissionais dispunham de um ethos próprio, em sua busca de legitimação social, ao firmar suas 'visões de mundo'. A medicina ocupa, dentre esses requisitos, lugar de excelência. Já a enfermagem, também de nível universitário, é vista como ainda em processo de profissionalização, por ainda não estar no 'estágio' da medicina. Falta-lhe autonomia, sobretudo em análise com o mercado de trabalho, onde não detém o monopólio, hoje competindo com modalidades de nível técnico. Para a autora, toda essa dificuldade está relacionada ao fato de que não conseguiu estabelecer sua diferenciação de corpo de conhecimentos teóricos e práticos e sua singularidade de serviço. Além do mais, a autonomia também está relacionada à prática liberal - que permite ao profissional controlar sua produção, distribuição e determinação do preço do serviço. Atualmente, a profissão medica já tem sido imersa em um processo de assalariamento e a uma burocratização do processo de trabalho. Já a enfermagem, que nunca foi liberal, busca ainda sua identidade de profissão (tipicamente feminina) diante da relação desigual com a medicina. E não terminam as diferenciações: A medicina, e seu corpo complexo de conhecimentos teóricos e práticos, pressupõe um longo processo de qualificação universitária e residência médica. Já a enfermagem é vista como a extensão do 'cuidado feminino' doméstico para o espaço hospitalar, ou seja, uma 'habilidade natural'. E por esse princípio, a enfermeira universitária ainda precisa concorrer com a técnica. Maia conclui que o ethos de ambas as profissões está fundado em uma ideia 'iluminista' da mulher, aquele que prendia a mulher ao discurso científico de sua natureza biológica. $\mathrm{Na}$ medicina, a mulher iluminista é a paciente. Na enfermagem, é a profissional.

A obstetrícia, entretanto, abre a guarda do monopólio 'técnico' médico, já que é uma especialidade que pode ser exercida por médicos e enfermeiras. Com a queda da fecundidade feminina, o mercado diminuiu consideravelmente, o que, de um lado, fez aumentar a competição e, do outro, fez diminuir o interesse médico por esse tipo de especialidade. Já o crescimento do interesse pelo modelo do parto humanizado criou uma noção diferenciada de expertise de mercado de trabalho: o próprio Ministério da Saúde, em busca da política de humanização, oficializou o reconhecimento da atuação da enfermagem para casos de parto normal sem complicações. Além do mais, as medidas do órgão de introduzir pagamentos pelo SUS, criar Centros de Parto Normal, também vieram a 
Resenha: análise da perspectiva comportamental e de 'ethos profissional' no estudo das políticas públicas de humanização do parto.

expandir o espaço.

Diante do que Maia considera um 'conflito político' na condução das assertivas para o parto humanizado, a autora utiliza o conceito do novo institucionalismo para compreender a dinâmica. Apresenta, a princípio, o estudo das organizações como um dos resultados do capitalismo industrial, quando se acreditava que os maiores benefícios da racionalidade e da cientificidade se davam nas organizações. A ideia foi refutada atualmente, quando sociólogos neoinstitucionalistas observaram que, além desses parâmetros não serem inerentes das organizações, estas são mais formalizadas por práticas culturais do que puramente racionais. Embora a função das organizações seja o oferecimento de bens e serviços à comunidade, este 'ideal' se esbarra na própria base em que existem: como arenas de disputas de valores, que possuem a instituição como as "regras do jogo". Analisar as organizações, para a autora, é primordial para o entendimento da ação social aqui delimitada. A definição é possível a partir da distinção entre os conceitos do ator racional e institucional. Enquanto o ator racional age em função de cálculos de custos e benefícios, movidos por critérios de maximização e utilidade; no modelo institucional, eles seguem as normas sem reflexão, baseados em interesses particulares. Ambos os modos não são excludentes, mas fazem parte de um continuum onde o indivíduo é mais ou menos racional, conforme a gama de situações em que está imerso. Enquanto o institucionalismo velho buscava no comportamento do indivíduo a explicação para a análise politica, o novo institucionalismo refuta essa ideia e busca o esclarecimento das ações a partir da mediação entre estrutura social e comportamento individual, ou seja, a instituição. Utilizado de modo mais efetivo nos estudos de procedimentos normativos de natureza macrossocial, o novo institucionalismo não perde seu caráter micro. Uma de suas vertentes, identificada por 'abordagem contextual interpretativa', reconhece o caráter macrossocietal das realidades, embora foque nos efeitos destas na dimensão micro. Ela parte da informação premissial de que a sociedade pós-industrial foi coberta de organizações baseadas em mitos institucionalizados enquanto 'princípios racionais da administração'. As atuais normas técnicas baseadas em eficiência viriam para tensionar as já institucionalizadas normas 'culturais'.

É nesta concepção, advinda de um modelo neoweberiano, que Maia se apoia ao utilizar o hospital como uma unidade de análise. Neste sentido, 
as características das organizações não são dicotômicas: ou formal, ou informal. São sistemas que abrigam setores burocratizados em meio a setores menos burocratizados, alguns mais impessoais e outros mais relacionais. Esse novo institucionalismo, segundo Maia, privilegia o cotidiano e a dimensão simbólica que arranja e rearranja as regras do comportamento organizacional.

O hospital, como uma organização que pode ter surgido por diversas motivações (ajudar carentes, ensinar novos médicos, etc.), torna-se exemplo dessa 'materialização de sentidos e objetivos'. E, portanto, é a partir dessa metodologia que a autora analisa os hospitais da cidade de Belo Horizonte e as tensões encontradas durante a implementação da política de humanização. Utilizando dados do Sinasc, a autora dividiu as unidades de saúde em tipologias: filantrópico, público, privado com SUS, privado sem SUS e cooperativa. A autora passa a analisar as missões dos hospitais, a fim de identificar algumas prioridades. Por fim, classifica como requisitos para facilitar ou limitar a implementação de políticas de humanização pontos como: localização, porte, complexidade, custos e relação de trabalho e remuneração.

O contrato de trabalho e a forma de remuneração do profissional médico traz considerações a respeito da influência da organização sobre o trabalho médico. Ao pesquisar essa relação de trabalho no hospital, Maia identificou uma disputa entre gestão hospitalar e seu interesse em realizar uma 'racionalidade administrativa', intervindo na autonomia médica. Uma das medidas adotadas pela direção com vistas em controlar a atividade dos trabalhadores foi a instalação do prontuário médico, que interpôs uma padronização nas condutas e medicamentos. A questão é que quando o cuidado na saúde dependia exclusivamente do que ela chama de 'fator trabalho', os médicos regulavam tanto a organização como os preços. Entretanto, recentemente surgiu o modo de remuneração assalariado e, com ele, os formatos de pré-pagamento, pós-pagamento e remuneração por tempo de serviço. No pagamento por tempo de serviço se incluem, por fim, o assalariamento e outras formas precárias que excluem benefícios formais. Ao analisar esses formatos de pagamento, conclui-se que o aspecto liberal e autônomo depende do contrato de trabalho e da remuneração, o que só é pleno na clínica privada.

A autora parte do pressuposto, no quarto capítulo, de que o hospital é a posição intermediária entre a política de humanização e a prática dos 
Resenha: análise da perspectiva comportamental e de 'ethos profissional' no estudo das políticas públicas de humanização do parto.

profissionais. Desse modo, faz uma análise do Estado - no caso, a prefeitura de Belo Horizonte - e sua intervenção nas diferentes organizações hospitalares. Analisa a atuação da Comissão Perinatal, instância da Secretaria municipal de Saúde, no monitoramento da qualidade de assistência materno-infantil naquela cidade. Criada em $1994 \mathrm{e}$ formalizada em 96, a Comissão tinha a finalidade de estudar, levantar recursos, propôr critérios e acompanhar a política assistencial da rede de assistência obstétrica neonatal. Com o passar do tempo, se ampliou para a participação de atores nao governamentais, passando também a discutir o modelo de assistência ao parto e a intervir nas direções de hospitais da saúde suplementar. Nas reuniões mensais que a autora participou, foram visualizados campos de conflito diversos, e a vitalidade da organização era concretizada com ações de capacitação de conselheiros, formação de doulas e acompanhamentos diversos em maternidades. Na década de 1990, a assistência hospitalar em Belo Horizonte era tida como precária sobretudo em decorrência do alto índice de mortes maternas. Maternidades com fins lucrativos foram descredenciadas, dando vazão a unidades hospitalares mais abertas ao modelo de humanização. Em 2007, a mesma Comissão Perinatal deflagrou um movimento de apoio ao parto normal, tendo a resistência apenas do hospital privado lucrativo, e do hospital universitário. Entre as ações empreendidas, estiveram a reforma de espaços físicos e discussões de aspectos éticos e legais dos modelos de assistência o tecnocrático e o humanizado.

O último item mencionado por Mônica Baia refere-se, por fim, ao conflito entre o discurso científico e a prática 'ritualística' na medicina. A prática médica, sobretudo no que diz respeito ao parto, está pouco orientada pela ciência. Ao mesmo tempo, desde a faculdade, estudantes associam o modelo de humanização a um 'retrocesso' e não concebem que, existindo hormônios sintéticos ou analgesia, eles não sejam empregados. Elabora-se uma 'oferta que cria a demanda', produzindo por fim as iatrogenias. Por fim, a total falta de hábito de uma educação continuada, ou de uma atualização científica, retira dos médicos a responsabilidade de atualizar os conhecimentos, mantendo-os no lugar seguro aprendido nas universidades.

A conclusão da autora começa com a seguinte constatação: falar da assistência ao parto no Brasil é falar, também, de desigualdade social ( p.164).Nesse ponto, a autora menciona que essa relação de submissão entre 
paciente e médico foi forjada dentro da organização hospitalar e se fortalece com ideias de que 'parto tem que aprender em manequim', com mulheres de classes populares, já que são elas atendidas em hospitais públicos e estes, por sua vez, são os únicos que se vinculam a faculdades. Os investimentos e custos com equipamentos também fazem com que o paciente, em segunda análise, se submeta a uma nova ordem: a da tecnologia. Desse modo, a própria organização do trabalho médico é restrita e sua dependência também é cada vez maior da tecnologia. Tornase parte do ethos essa formação hospitalar centrada em procedimentos tecnológicos, e não relacionais. De liberal, o médico se reestrutura em um conjunto de práticas desiguais identificadas como 'medicina tecnológica'. Já o hospital se torna independente, inclusive financeiramente, do trabalho e da autonomia médicos.

Conforme a autora diagnostica: o modelo tecnocrático embasa uma prática institucionalizada que, por sua vez, legitima outras instituições: os hospitais, a medicina, a tecnologia dura, a imagem iluminista da mulher(p.165). Segue acrescentando que o argumento ético não é o suficiente para convencer a organização hospitalar de que o modelo humanizado é o melhor, diante do comprometimento com valores, como o ganho financeiro e a reificação da tecnologia. Desse modo, nem mesmo uma mudança na estrutura física facilitaria a mudança de paradigma. Tanto que, ainda que alguns dos itens preconizados pela política - como o direito a acompanhante - sejam postos em prática em algumas unidades, não se pode dizer que a organização esteja de fato se humanizando, já que uma parcela dessa mudança requer uma modificação direta nas relações entre médicos e gestantes. A vinculação com o SUS, segundo a autora, foi uma das únicas forças que se interpôs para estabelecer humanização em hospitais privados, entretanto nem mesmo essa diferenciação é destacada de maneira uniforme: a organização hospitalar deve ser considerada. Enquanto os hospitais privados sem SUS encontram-se extremamente afastados do intento de modificar o modelo de assistência, os hospitais públicos apresentam um pouco mais de abertura - ainda que de modo heterogêneo. Por fim, os hospitais privados que atendem pelo SUS situamse em ponto intermediário.

Além da identidade das organizações, a autora afirma que também o campo de conflito entre profissionais da obstetrícia - médicos e enfermeiras - deve ser colocado em evidência: cada profissão exerce um tipo diferente 
Resenha: análise da perspectiva comportamental e de 'ethos profissional' no estudo das políticas públicas de humanização do parto.

de cuidado; além do mais, a obstetrícia tem perdido espaço na medicina, enquanto que é vista como um novo 'nicho' para atuação independente da enfermagem. Esse tipo de embate só pode ser solucionado, quando da possibilidade de um trabalho em equipe, sem estabelecimento de hierarquias, evitando a ação individualizada. Segundo a autora, para um atendimento humanizado é imprescindível o trabalho em cooperação. A perda da autonomia liberal é que é considerado o eixo de discussões sobre a mudança do ethos médico, porque, segundo a autora, uma autonomia liberal como sinônimo de boa assistência e a ideia de que existe uma autonomia plena são dois equívocos. A questão real é saber, reforça a autora, a qual constrangimento é legítimo se submeter (p.169). Diante de todo esse diagnóstico, a autora acredita que, enquanto experiência única em todo o País, a Comissão Perinatal inova ao trazer a tona, para além dos discursos éticos, o jogo político para sua esfera de ação, com disputas levadas a público em reuniões.

Com considerações fundamentadas historicamente, o livro de Maia consegue estabelecer distinções teórico-metodológicas que valem ser notadas, ao não tomar em seu estudo - basicamente orientado pela sociologia das profissões - um ethos estritamente ideológico e funcionalista baseado no interesse do 'bem coletivo'. A autora não se furtou de apresentar a divisão de classes, as disputas mercadológicas, as práticas monopolistas, e a perda progressiva da autonomia do trabalho médico pelo processo de hospitalização, ainda que veja com 'bons olhos' essa perda. Ao que indica, os estudos da autora se inserem no que Durand (1975) resgata como o 'fenômeno tecnocrático', que permite a concepção de que o poder antes fundado estritamente na propriedade pode transitar por poderes associados à ciência e à técnica.

Entretanto, a concepção da autora punha a divisão do trabalho como um processo que se mantêm através de valores - nesse ponto, ela situa entre os valores os fins remuneratórios, e a reserva de mercado. A partir disso, as soluções observadas são também centradas em mecanismos simbólicos: por exemplo, a reorganização de 'trabalho em equipe' a partir de políticas públicas que moldem o comportamento do trabalhador da saúde através da pregação ética. Essa valorização da dimensão simbólica seria acompanhada por um Estado vigilante - cristalizado na Comissão Perinatal - e entendido como solucionador de 'constrangimentos', ou cujas normativas técnicas por um novo 'paradigma' teriam por missão 
reestruturar.

É preciso salientar, neste ponto, que embora as características do neo-institucionalismo possam ter sido visualizadas com clareza nessa relação imediata entre a implementação das normativas por um modelo 'humanizado' e a resistente organização do trabalho atualmente tecnocrática, a perspectiva apresentada termina por ser extremamente pontual, não explorando determinações sociais de natureza estrutural, que se seguem para além dos ethos de cada profissão - e que, inclusive, têm função definidora destes. Lima (2011) reforça que:

(...) apesar da reconhecida importância das instituições na sociedade, as políticas públicas, particularmente as políticas sociais, são condicionadas por variáveis estruturais, que o referencial neo-institucionalista pode não dar conta de abarcar. (Lima, 2011, p.130).

Se Maia afirma que a institucionalização do parto em seu modelo tecnocrático é o que tem moldado e reforçado tantas distorções como: a organização hospitalar, a imagem iluminista da mulher, a medicina, etc, como tentar esquivar seus efeitos nocivos restringindo as ações à proposição de novos valores na organização das funções? Mais: considerando o crescimento avassalador do mercado privado de saúde no Brasil, como acreditar no sucesso das políticas públicas cujas normativas só determinam metas para trabalhadores do cada vez mais precário e sugado Sistema Único de Saúde? É possível acreditar em um Estado focado em interesses coletivos, diante desse crescente movimento de privatização, compra de serviços - que a autora identifica como hibridismo - e contratações precárias?

Ao nosso ver, segue a sugestão de re-situar as políticas públicas estatais dentro do rol mais amplo de atuações, para entender se as normativas determinadas aos trabalhadores têm coerência ou são contraditórias com as demais medidas na atenção à saúde: prioridade nos financiamentos, remuneração e condições de trabalho. A constatação de que o Brasil é o segundo país com maior mercado de saúde suplementar fornece-nos indícios importantes de que, conforme Marx já afirmava, o Estado é importante equipamento ideológico do capital. No que diz respeito ao mundo do trabalho, uma contribuição de natureza estrutural que pode fornecer, inclusive, elementos contextuais relevantes para o entendimento da criticada 'tecnocracia' - e de todos esses efeitos minuciosamente apresentados por Maia- é a reestruturação produtiva a 
Resenha: análise da perspectiva comportamental e de 'ethos profissional' no estudo das políticas públicas de humanização do parto.

subsunção formal dos trabalhadores no setor de serviços ao metabolismo capitalista.

Surgido na década de 1970, esse novo modo de produção surgiu como resposta à crise do capital que se figurava como em decorrência de um 'esbanjamento' do Estado do Bem Estar Social - da era fordista e taylorista, onde a padronização da produção, feita em massa e concentrada em fábrica, gerou um excesso de mercadorias que demandava necessidade de acrescer as possibilidades de consumo. A crise que culminou com a flexibilização produtiva, e a necessidade de baratear ainda mais a força de trabalho com redução de benefícios aos trabalhadores, terminou por gerar subempregos e aumentar o número de desemprego, concorrência, e redução dos gastos estatais com direitos sociais através da adoção do Estado Mínimo.

Esse modelo se estendeu ao setor de serviços, culminando uma metamorfose que inclui todos os setores de produção no que Antunes (1995) define como a classe-que-vive-do-trabalho. Países periféricos do capitalismo, como o Brasil, que já amargavam mais intensamente a desigualdade social, terminaram por sofrer ainda mais os efeitos da fragmentação, complexificação e heterogeneização da classe trabalhadora. Levando esta reflexão para o trabalho na saúde, é possível identificar que a intensificação do trabalho e a polivalência tornam-se critérios de inclusão e permanência no mercado muito mais 'urgentes' aos trabalho subsumido pelo capital, do que a 'ética' baseada na humanização; além do mais, a exigência por produtividade, o controle de tempo, seja para aumento do ganho financeiro ou para o desafogamento das maternidades do SUS lotadas pela ausência de estrutura do sistema público, tornam-se 'normas' muito mais concretas do que as preconizações de padrões comportamentais 'humanizados'.

\section{Bibliografia consultada:}

ANTUNES, Ricardo. Adeus ao trabalho? Ensaio sobre as metamorfoses e a centralidade do Mundo do Trabalho. São Paulo, Cortez / Unicamp, 1995.

DURAND, José Carlos Garcia. A serviço da coletividade: crítica à sociologia das profissões. Rev. adm. Empres. São Paulo: 1975. Disponível em: 
Wanessa Oliveira Silva

http://www.scielo.br/scielo.php?script=sci_arttext\&pid=S0034-

75901975000600005\&lng=en\&nrm=iso. Acesso em 2 de fevereiro de 2014.

LIMA, L.D.; MACHADO, C.V.; GERASSI, C.D.O neo-institucionalismo e a análise de políticas de saúde: contribuições para uma reflexão crítica.In MATTOS, R. A.; BAPTISTA, T. W. F. Caminhos para análise das politicas de saúde, 2011. p.111-137.

Enviado:

05.02.2014

Aprovado:

04.07.2014 